\title{
Forced degradation of gliquidone and development of validated stability-indicating HPLC and TLC methods
}

\author{
Mohamed Refaat El-ghobashy ${ }^{1}$, Ali Mohamed Yehia ${ }^{1}$, Aya Helmy Helmy*2, Nadia Fayek Youssef ${ }^{2}$ \\ ${ }^{1}$ Analytical Chemistry Department, Faculty of Pharmacy, Cairo University, Cairo, Egypt, ${ }^{2}$ Pharmaceutical Chemistry
Department, National Organization for Drug Control and Research (NODCAR), Giza, Egypt
}

\begin{abstract}
Forced degradation studies of gliquidone were conducted under different stress conditions. Three degradates were observed upon using HPLC and TLC and elucidated by LC-MS and IR. HPLC method was performed on $\mathrm{C}_{18}$ column using methanol-water $(85: 15 \mathrm{v} / \mathrm{v}) \mathrm{pH} 3.5$ as a mobile phase with isocratic mode at $1 \mathrm{~mL} \cdot \mathrm{min}^{-1}$ and detection at $225 \mathrm{~nm}$. HPLC analysis was applied in range of $0.5-20 \mu \mathrm{g} \cdot \mathrm{mL}^{-1}$ $(\mathrm{r}=1)$ with limit of detection (LOD) $0.177 \mu \mathrm{g} \cdot \mathrm{mL}^{-1}$. TLC method was based on the separation of gliquidone from degradation products on silica gel TLC $\mathrm{F}_{254}$ plates using chloroform-cyclohexaneglacial acetic acid $(6: 3: 1 \mathrm{v} / \mathrm{v})$ as a developing system with relative retardation $1.15 \pm 0.01$. Densitometric measurements were achieved in range of $2-20 \mu \mathrm{g} / \mathrm{band}$ at $254 \mathrm{~nm}(\mathrm{r}=0.9999)$ with LOD of $0.26 \mu \mathrm{g} / \mathrm{band}$. Least squares regression analysis was applied to provide mathematical estimates of the degree of linearity. The analysis revealed a linear calibration for HPLC where a binomial relationship for TLC. Stability testing and methods validation have been evaluated according to International Conference on Harmonization guidelines. Moreover, the proposed methods were applied for the analysis of tablets and the results obtained were statistically compared with those of pharmacopeial method revealing no significant difference about accuracy and precision.
\end{abstract}

Keywords: Gliquidone/forced degradation/stability-indicating. HPLC/method validation. TLC/method validation.

\section{INTRODUCTION}

Gliquidone is 1, 1-cyclohexyl-3-\{4-[2-(3, 4-dihydro7-methoxyy-4, 4-dimethyl-1, 3- dioxo-2 $(1 \mathrm{H})$ - isoquinolyl) ethyl benzene sulphonyl] \} urea. It is a sulfonylurea derivative used as oral anti-diabetic drug for the treatment of type 2 diabetes mellitus. The drug is given as a supplemental therapy followed by diet modification and improves the glycemic control as well as reducing the blood sugar level (Brayfield, 2014). Gliquidone is official in BP(Brithish Pharmacopeia, 2016). Literature survey revealed that quantitation of gliquidone has been achieved by UV spectrophotometry (Arayne, Sultana, Mirza, 2006), LC-MS (Maurer et al., 2002) and HPLC in dosage form and biological fluids (Arayne et al., 2010a; Arayne et al., 2010b; Guo et al., 1992; Sridevi, Diwan, 2000). Recently, spectrofluoremetric normal and

\footnotetext{
*Correspondence: A. H. Helmy. Pharmaceutical Chemistry Department, National Organization for Drug Control and Research (NODCAR), 6 Abo-Hazem Street, Haram, Giza, Egypt. E-mail: aya_helmy26@yahoo.com
}

derivative synchronous methods have been published for the determination of gliquidone in drug substance and drug products (El-Ghobashy et al., 2018). To date, no stability -indicating method has been described in the literature and no previous studies focused on gliquidone degradation have been performed. As per regulatory requirements for registration of new drugs, stress degradation should be applied. Therefore, forced degradation studies involving gliquidone will increase the chemical information about the degradation products of active pharmaceutical ingredients in both pure and pharmaceutical forms (Görög, 2000) offering a scientific impact for the present novel work. In addition, the stress testing to identify the degradation of the molecule can be further used to develop stability-indicating methods of analysis (FDA, 2000). A stability-indicating method accurately measures the changes in active ingredient concentration without interference from other degradation products, impurities and excipients (ICH, 2003a).

The goals of the present study are: i) to perform a forced degradation study of gliquidone according to the ICH guidelines; ii) to elucidate the chemical structure 
of the degradation products; iii) to develop and validate HPLC and TLC methods able to quantify the drug even in the presence of the its degradation products.

\section{EXPERIMENTAL}

\section{Material and chemicals}

Drug substance, gliquidone working standard (99.36\%) was kindly supplied by Mina Pharm Company, Cairo, Egypt. Drug product, Glorenor ${ }^{\circledR}$ tablets, batch No. EIE2313 Mina pharm under license of Menarini -Italy labeled to contain $30 \mathrm{mg}$ gliquidone per each tablet and was purchased from commercial sources in the local market. HPLC grade methanol (Macron Poland), ethanol (Sigma Aldrich, USA), water-in house was bi-distilled. Chloroform (Sigma Aldrich), cyclohexane (S.D. fine-chem limited, Mumbai, India), glacial acetic acid (Piochem Egypt). Sodium hydroxide extra pure $98 \%$ (Lobachem Mumbai, India), hydrochloric acid 37\% (Honeywell) and hydrogen peroxide $30 \%$ (Panreac) were analytical grade.

b. Instrumentation and chromatographic conditions

For HPLC: an HPLC system (Agilent Technology 1260 series, USA) equipped with G1314F UV detector, G1311C quaternary pump, G1316A column oven, Agilent 1260 series vacuum degasser, and 20 microliter loop manual injector was used. HPLC separation and analysis were performed on $\mathrm{C} 18,250 \mathrm{~mm} \times 4.6 \mathrm{~mm}, 10 \mu \mathrm{m}$, column (Phenomenex ${ }^{\circledR}$, USA). The mobile phase consisted of methanol and water $\mathrm{pH} 3.5$ adjusted with ortho-phosphoric acid (85:15 v/v) using a pH meter (Jenway 3510, England). An isocratic elution with a flow rate of $1 \mathrm{~mL} \cdot \mathrm{min}^{-1}$ was kept throughout the analysis and the detection was achieved at $225 \mathrm{~nm}$. The column was conditioned for $\geq 30 \mathrm{~min}$ at ambient temperature $\left(25 \pm 2{ }^{\circ} \mathrm{C}\right)$. Data were recorded and analyzed by Chemstation ${ }^{\circledR}$ software (Agilent, USA). A mixture of methanol-water in the ratio of $(85: 15 \mathrm{v} / \mathrm{v})$ was used as a diluent for the working solutions. All solutions were filtered through $0.45 \mathrm{~mm}$ nylon membrane filter before HPLC injections.

For TLC- densitometry: CAMAG scanner 3 plus and CAMAG TLC sampler linomat IV (CAMAG, Multenz, Switzerland) supplied with a $100 \mu \mathrm{L}$ syringe for TLCdensitometric determinations. The following parameters were taken into consideration; slit dimension: $6 \times 0.3 \mathrm{~mm}$; scanning speed: $20 \mathrm{~mm} / \mathrm{s}$; data resolution: $100 \mu \mathrm{m} / \mathrm{step}$; bandwidth: $6 \mathrm{~mm}$. Results output: chromatograms and integrated peak areas of WINCATS software. TLC aluminum plates $(20 \times 10)$ were coated with $0.25 \mathrm{~mm}$ silica gel $60 \mathrm{~F}_{254}$ (Merck, Germany) and chloroform - cyclohexane -glacial acetic acid $(6: 3: 1 \mathrm{v} / \mathrm{v})$ was used as a developing system.
For LC- MS: an Agilent technology 6420 triple Quad LC/MS consisting of a G1311A gradient quaternary pump, G1329A auto injector, and the G6420A MS detector was employed. HPLC separation was performed on $\mathrm{C} 18,60 \times 4.6 \mathrm{~mm}, 5 \mu \mathrm{m}$, column (BD, USA). The mobile phase consisted of a mixture of acetonitrile and acidified water $(0.075 \%$ formic acid) at a flow rate $0.7 \mathrm{~mL} \cdot \mathrm{min}^{-1}$ (Table I). Nitrogen and gas temperature of $270{ }^{\circ} \mathrm{C}$ with a flow of 10 liter/min and nebulizer of 50 pounds per square inch (psi) were used. The ionization mode was ESI and the data were analyzed by Mass Hunter ${ }^{\circledR}$ software.

For IR spectroscopy: NICOLET 6700, FT - IR Thermo SCIENTIFIC - CLASS 1 LASER PRODUCT (USA) using KBr disc, Mini - Pellet Press and OMNIC software for data output.

TABLE I - Gradient elution of LC-MS mobile phase

\begin{tabular}{ccc}
\hline \multirow{2}{*}{ Time (min) } & \multicolumn{2}{c}{ Mobile phase composition (\%) } \\
\cline { 2 - 3 } & Acetonitrile & Acidified water \\
\hline 2.57 & 13 & 87 \\
2.66 & 35 & 65 \\
7.71 & 35 & 65 \\
7.80 & 50 & 50 \\
16.29 & 50 & 50 \\
16.36 & 75 & 25 \\
\hline
\end{tabular}

\section{Preparation of degradation product and stock standard solutions}

\section{Acid hydrolytic degradation}

Gliquidone $(50 \mathrm{mg})$ was refluxed for 9 hours with different concentrations of $50 \mathrm{~mL}$ ethanolic hydrochloric acid $(1 \mathrm{M} ; 2 \mathrm{M} ; 3 \mathrm{M} ; 4 \mathrm{M})$ and the same concentration was left in 0.1-3 M ethanolic hydrochloric acid at room temperature for 3 days. After this period, each solution was neutralized, filtered, evaporated using a water bath, and had the volume reconstituted with methanol to produce concentration equivalent to $1 \mathrm{mg} \cdot \mathrm{mL}^{-1}$.

\section{Base hydrolytic degradation}

Gliquidone $(50 \mathrm{mg}$ ) was refluxed for 9 hours with distinct concentrations of $50 \mathrm{~mL}$ ethanolic sodium hydroxide ( $1 \mathrm{M} ; 2 \mathrm{M} ; 3 \mathrm{M} ; 4 \mathrm{M})$ and the same concentration was left in 0.1-3 M ethanolic sodium hydroxide at room temperature for 3 days. After this period, each solution was neutralized, filtered, evaporated using a water bath, and had the volume reconstituted with methanol to produce concentration equivalent to $1 \mathrm{mg} \cdot \mathrm{mL}^{-1}$. 


\section{Neutral hydrolytic degradation}

$50 \mathrm{mg}$ of gliquidone was refluxed with $50 \mathrm{~mL}$ of bi-distilled water for 5 hours and filtered, evaporated using water bath and completed to volume with methanol $\left(1 \mathrm{mg} \cdot \mathrm{mL}^{-1}\right)$.

\section{Oxidative degradation}

$50 \mathrm{mg}$ of gliquidone was refluxed with $50 \mathrm{~mL}$ of $30 \%$ hydrogen peroxide for 5 hours, filtered, evaporated using a water bath and completed to volume with methanol $\left(1 \mathrm{mg} \cdot \mathrm{mL}^{-1}\right)$.

\section{Thermal degradation}

$100 \mathrm{mg}$ of gliquidone in solid state was spread to $1 \mathrm{~mm}$ thickness in a Petridish and kept in the oven (Memmert UM-400, Germany) at $40^{\circ} \mathrm{C}$ and $80{ }^{\circ} \mathrm{C}$ for 4 hours. $10 \mathrm{mg}$ of each sample was taken into $10-\mathrm{mL}$ volumetric flask, dissolved and diluted with methanol.

\section{Stress degradation studies}

From hydrolytic, oxidative and thermal degradation solutions ( $\left.1 \mathrm{mg} \cdot \mathrm{mL}^{-1}\right)$, different aliquots were transferred into $10-\mathrm{mL}$ volumetric flasks and diluted to the mark with methanol for the primary trials. Samples were analyzed by HPLC and TLC in order to evaluate the stability of intact drug towards these stress conditions. The basic hydrolytic degradation was analyzed by LC-MS. Moreover degradation solution was applied in bands on silica gel glass plates and developed in chloroform -cyclohexane glacial acetic acid $(6: 3: 1 \mathrm{v} / \mathrm{v})$. Each of the isolated bands was extracted from silica with methanol, air dried and IR spectra were scanned. All collected samples were kept in refrigerator at $5^{\circ} \mathrm{C} \pm 2$.

\section{Standard stock solutions}

For HPLC, Gliquidone $0.2 \mathrm{mg} \cdot \mathrm{mL}^{-1}$ was prepared in methanol; further dilution with the diluent to obtain a solution of $20 \mu \mathrm{g} \cdot \mathrm{mL}^{-1}$. For TLC, Gliquidone $1 \mathrm{mg} \cdot \mathrm{mL}^{-1}$ was prepared in methanol.

Laboratory prepared mixtures solutions containing different ratios of gliquidone and its alkaline degradation products were prepared to contain $10-80 \% \mathrm{w} / \mathrm{w}$ of alkaline degradation for HPLC and TLC.

\section{Preparation of calibration curves}

\section{HPLC method}

Aliquots of standard solution $20 \mu \mathrm{g} \cdot \mathrm{mL}^{-1}$ equivalent to 5-200 $\mu \mathrm{g}$ of gliquidone were transferred into a series of $10-\mathrm{mL}$ volumetric flasks, and the volume was completed with the diluent. Triplicate injections of each dilution were eluted at flow rate $1 \mathrm{~mL} \cdot \mathrm{min}^{-1}$ on a $\mathrm{C} 18$ column using methanol - water at $\mathrm{pH} 3.5$ adjusted with ortho-phosphoric acid $(85 / 15 \mathrm{v} / \mathrm{v})$ as the mobile phase. The integrated peak areas were recorded at $225 \mathrm{~nm}$ under the specified chromatographic conditions. Calibration curve was prepared by plotting peak areas versus the concentration 0.5- $20 \mu \mathrm{g} . \mathrm{mL}^{-1}$ and the regression equation was computed.

\section{TLC-densitometric method}

Aliquots of standard solution $1 \mathrm{mg} \cdot \mathrm{mL}^{-1}$ equivalent to 2 to $20 \mu \mathrm{g} / \mathrm{b}$ and were spotted on precoated TLC plates using CAMAG linomat IV applicator under a nitrogen stream. The procedure was carried out as under "Instrumentation and chromatographic conditions" and plates were developed for up to $8 \mathrm{~cm}$ at room temperature in a chromatographic chamber previously saturated for $30-45$ minutes. The plates were air dried and densitometric measurements were performed at $254 \mathrm{~nm}$ in absorbance mode with the CAMAG TLC scanner 3 as under the specified instrumental conditions. The calibration curve was prepared by plotting the peak areas versus the concentration 2-20 $\mu \mathrm{g} / \mathrm{band}$ and regression equation was computed.

\section{Assay of Glorenor ${ }^{\circledR}$ tablets}

\section{Using HPLC method}

Twenty tablets were accurately weighed, crushed to a fine powder. An accurately weighed portion equivalent to $60 \mathrm{mg}$ of gliquidone was transferred to $250-\mathrm{mL}$ beaker, extracted with $40 \mathrm{~mL}$ methanol by shaking for 30 min using an ultrasonic bath (sonamac), filtered into $100-\mathrm{mL}$ volumetric flask and diluted to volume with the same solvent. Further dilution with the HPLC diluent to obtain an $18 \mu \mathrm{g} . \mathrm{mL}^{-1}$ solution. The procedure detailed under "preparation of calibration curve "was followed and gliquidone concentration was calculated using the corresponding regression equation.

\section{Using TLC-densitometric method}

Aliquots of the same tablets solution $\left(60 \mathrm{mg} .100 \mathrm{~mL}^{-1}\right)$ covering the working concentration range were spotted and the procedure under "preparation of calibration curve" was performed and gliquidone concentration was calculated using the corresponding regression equation.

\section{RESULTS AND DISCUSSION}

\section{Results of forced degradation studies}

The results of stability study were confirmed by HPLC, TLC and three degradates were observed and 
elucidated by LC-MS analysis and IR-spectroscopy. Gliquidone was found to be stable under thermal conditions at $40{ }^{\circ} \mathrm{C}$ and $80{ }^{\circ} \mathrm{C}$ for 4 hours (data not show). Partial degradation was observed under neutral hydrolytic and oxidative $\left(30 \% \mathrm{H}_{2} \mathrm{O}_{2}\right)$ conditions for 5 hours (Figure 1a-b). Significant degradation was observed in $0.1 \mathrm{M}-3 \mathrm{M}$ ethanolic $\mathrm{HCl}$ or ethanolic $\mathrm{NaOH}$ at room temperature for 3 days or refluxing for 7 hours (data not show). A complete degradation of gliquidone was produced only upon using $4 \mathrm{M}$ ethanolic $\mathrm{HCl}$ and $4 \mathrm{M}$ ethanolic $\mathrm{NaOH}$ under reflux for 9 hours and the same peaks were observed in both conditions as shown in Figure 1c, d. The solutions were subjected to HPLC and TLC analysis to establish the number of products formed. The chromatographic profiles of the degradation products formed under $4 \mathrm{M}$ ethanolic $\mathrm{HCl}$ and $4 \mathrm{M}$ ethanolic $\mathrm{NaOH}$ conditions are presented in Figure $1 \mathrm{c}-\mathrm{d}$, respectively. In both conditions peaks with same retention time were obtained.

\section{Elucidation of the degradation products}

LC/MS analysis: solution of base degradation was subjected to LC-MS analysis and mainly 3 degradation products were detected. Suggested chemical formula and $\mathrm{m} / \mathrm{z}$ were $\mathrm{C}_{8} \mathrm{H}_{12} \mathrm{~N}_{2} \mathrm{O}_{2} \mathrm{~S}(200.26)$ degradate $\mathrm{I}, \mathrm{C}_{41} \mathrm{H}_{40} \mathrm{~N}_{4} \mathrm{O}_{9} \mathrm{~S}$ (764.84) degradate II and $\mathrm{C}_{20} \mathrm{H}_{25} \mathrm{~N}_{3} \mathrm{O}_{4} \mathrm{~S}$ (403.49) degradate III. Gliquidone and suggested degradates structures were shown in Figure 2a, b, c and d.

IR spectra (Cross, 1964): IR spectrum of degradate I Figure 2b, $\mathrm{C}=\mathrm{O}$ amide stretching; cyclohexyl groups; gem-dimethyl groups and $\mathrm{CH}$-stretching at $2857 \mathrm{~cm}^{-1}$ of - $\mathrm{O}-\mathrm{CH}_{3}$ were absent ,but 3467 (NH stretching), 1648 ( $\mathrm{NH}$ bend), 1560 ( $\mathrm{NH}$ bend, indicate $-\mathrm{SO}_{2} \mathrm{NH}$ ) and $11332,1165(\mathrm{~S}=\mathrm{O}$ stretch$)$ were present. The main groups of gliquidone IR spectrum Figure 2a, were observed in degradate II and suggested to form a more conjugated molecule Figure 2c. The presence of NH-stretching

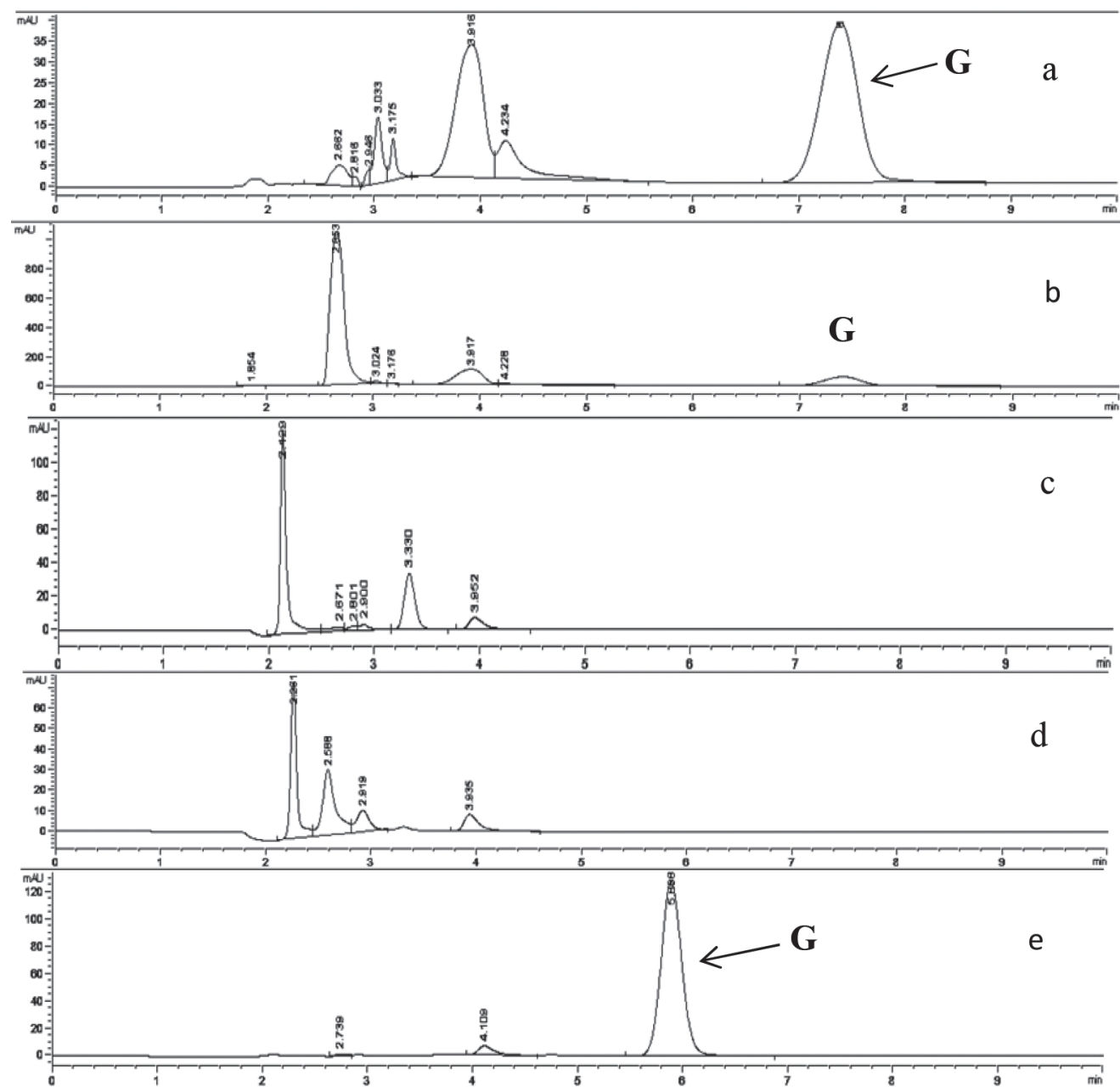

FIGURE 1 - Original chromatograms of a) neutral hydrolytic degradation, b) oxidative degradation, c) acid hydrolytic degradation, d) base hydrolytic degradation and e) intact gliquidone $(\mathrm{G})\left(20 \mu \mathrm{g} \cdot \mathrm{mL}^{-1}\right)$ with retention time 5.8 minutes. 
at $3502 \mathrm{~cm}^{-1}$; $\mathrm{NH}$-amide at $1649 \mathrm{~cm}^{-1} ; \mathrm{C}=\mathrm{O}$ at 1713 , $1676 \mathrm{~cm}^{-1}$; NH-bend at $1558 \mathrm{~cm}^{-1}$ indicate $-\mathrm{SO}_{2} \mathrm{NH}-$ sulfonamide group; $\mathrm{S}=\mathrm{O}$ stretching at $1338 \mathrm{~cm}^{-1}$; and cyclohexyl groups of $2930,1456,1260 \mathrm{~cm}^{-1}$ were an indication of degradate III Figure 2d.

\section{Methods development}

\section{HPLC method}

Stability-indicating HPLC method has been, optimized, developed, and validated for the separation and determination of gliquidone in presence of degradation products Figure 1(a-e). The three components of HPLC method: column type, mobile phase composition and aqueous phase $\mathrm{pH}$ were studied and asymmetry was a function of judgment. The optimum ratio of mobile phase composition was found to be methanol - water $(85: 15 \mathrm{v} / \mathrm{v})$. Water with $\mathrm{pH}$ value 3.5 offered a good symmetry, this $\mathrm{pH}$ is about $1 \mathrm{pH}$ unit below $\mathrm{pKa}$ of the acidic drug (4.3) hence the uncharged form is obviously predominant and high retention on $\mathrm{C}_{18}$ stationary phase is observed. Working at a more acidic $\mathrm{pH}$ has an unfavorable effect on column lifetime; therefore $\mathrm{pH} 3.5$ was optimized for peak symmetry and column capacity of gliquidone. Moreover, $\mathrm{C}_{18}$ column phenomenex ${ }^{\circledR} 10 \mu \mathrm{m} 250 \times 4.6 \mathrm{~mm}$ improves the peak shapes and resolution of gliquidone and its degradation products Figure 1(a-e). The gliquidone $(\mathrm{Rt}=5.9 \pm 0.03 \mathrm{~min})$ and the degradation products (I: Rt=2.26 min; II: Rt $=2.58 \mathrm{~min}$; III $=2.91 \mathrm{~min}$ ) were detected at the maximum wavelength of absorption
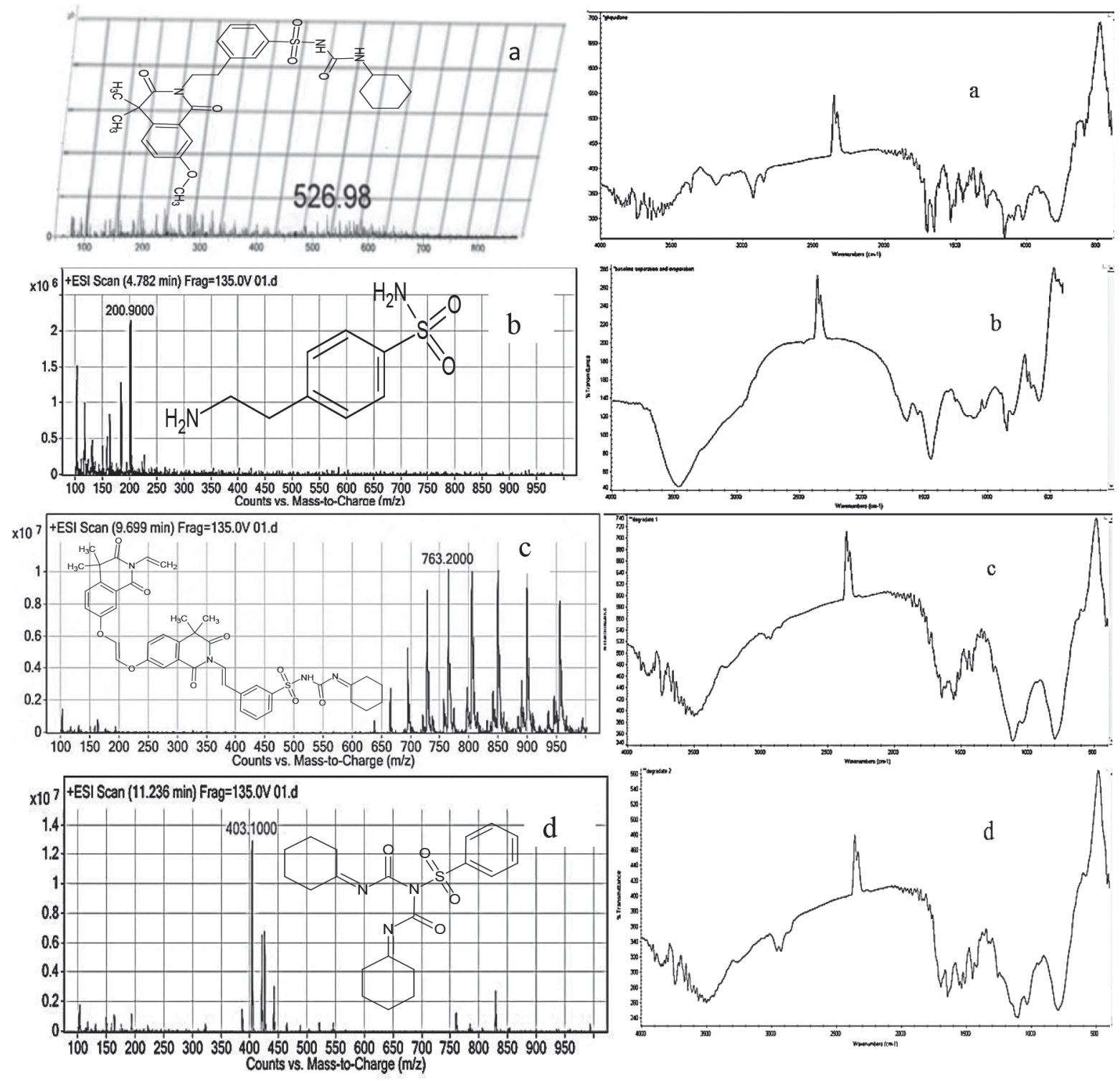

FIGURE 2 - LC-MS, suggested structures and IR spectra of a) gliquidone, b) degradate I, c) degradate II and d) degradate III. 
(225 nm). Final conditions: 20 microliter injection volume, $1 \mathrm{~mL} \cdot \mathrm{min}^{-1}$ flow rate, $25^{\circ} \mathrm{C}$ temperature, phenomenex ${ }^{\circledR}$ $\mathrm{C}_{18}(250 \mathrm{~mm} \times 4.6 \mathrm{~mm}$ I.d., $10 \mu$ particle diameters $)$ and methanol- water $\mathrm{pH} 3.5(85 / 15 \mathrm{v} / \mathrm{v})$ were found to be ideal for HPLC performance.

\section{TLC method}

TLC-densitometric method was developed for the resolution of gliquidone from its degradation products on
TLC aluminum plates, coated with silica gel $60 \mathrm{~F}_{254}$ as a stationary phase Figure $3 \mathrm{~b}$. The best developing system was found to be chloroform, cyclohexane and glacial acetic acid in the ratio of $(6: 3: 1 \mathrm{v} / \mathrm{v})$ showing $R_{\mathrm{f}}$ values $0.60 \pm 0.01$ for gliquidone, and $0.01 \pm 0.01,0.24 \pm 0.01,0.52 \pm 0.01$ for the degradation products I, II, III respectively Figure 3a and the calculated relative retardation factor $\left(\mathrm{R}_{\mathrm{ret}}\right)$ was found to equal $1.15 \pm 0.01$, revealing a good separation of the drug from its degradation products. Different scanning
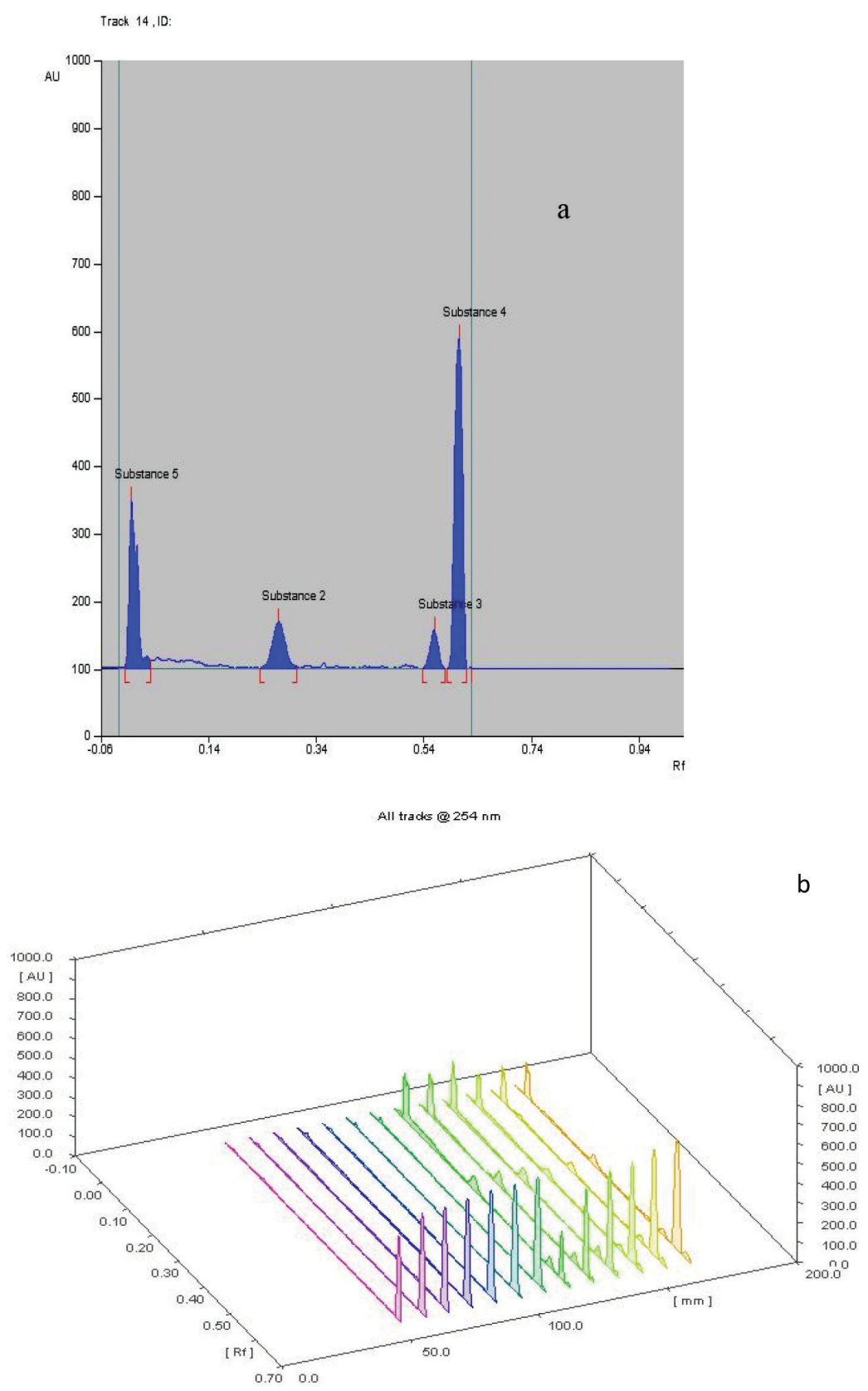

FIGURE 3 - a) 2D TLC-densitogram of separated peaks of gliquidone ( $R f 0.60 \pm 0.01$ ) and the 3 degradation products (Rf degradate. I $0.01 \pm 0.01$, degradate. II $0.24 \pm 0.01$, degradate. III $0.0 .52 \pm 0.01)$ and b) $3 \mathrm{D}$ TLC densitogram of gliquidone $\operatorname{Rf}(0.6 \pm 0.01)$ in the concentration range ( $2-20 \mu \mathrm{g} / \mathrm{band})$, and a mixture of gliquidone and the 3 degradation products using (chloroform-cyclohexaneglacial acetic acid) $(6: 3: 1 \mathrm{v} / \mathrm{v})$ as a developing system at $254 \mathrm{~nm}$. 
wavelengths were tested $(225,254$ and 312$)$ to obtain good sensitivity with minimum noise. The slit dimensions of the scanning light beam should ensure complete coverage of band dimensions without interference of the adjacent band and $6 \times 0.3 \mathrm{~mm}$ was proved to be the slit dimension of choice that provided highest sensitivity and scanning at wavelength $254 \mathrm{~nm}$. Gliquidone was successfully resolved from its degradation products upon using the mentioned conditions.

\section{Method validation}

The suggested HPLC and TLC methods were validated according to ICH guidelines (ICH, 2003b) for specificity, linearity, accuracy, precision and robustness to demonstrate that the developed procedures are sensitive, selective, accurate, precise and suitable for their intended use and to be used for QC analysis of gliquidone in drug substance and pharmaceutical product.

\section{Specificity}

Specificity could be demonstrated by the resolution of gliquidone and its degradation products as shown in representative HPLC Figure 1a-e and TLC Figure 3a-b Chromatograms. The presented HPLC and TLC methods were specific for identification and quantification of gliquidone in tablets without interference of excipients namely lactose, starch, pregelatinized starch and magnesium stearate (Torrinomedica, 2015).

\section{Linearity/range}

Linearity was established by analysis of samples in concentration range $0.5-20 \mu \mathrm{g} \cdot \mathrm{mL}^{-1}$ by HPLC and $2-20 \mu \mathrm{g} / \mathrm{b}$ and by TLC. For HPLC method, the linear relationship in the concentration range was evaluated by calculation of the regression line by the method of least squares Figure 4a. However, for TLC method, regression data were statistically analyzed and found to be binomial regression to provide mathematical estimates of the degree of linearity Figure 4b. Correlation coefficient, y intercept, slope of the regression line and the residual sum of squares were listed in Table II.
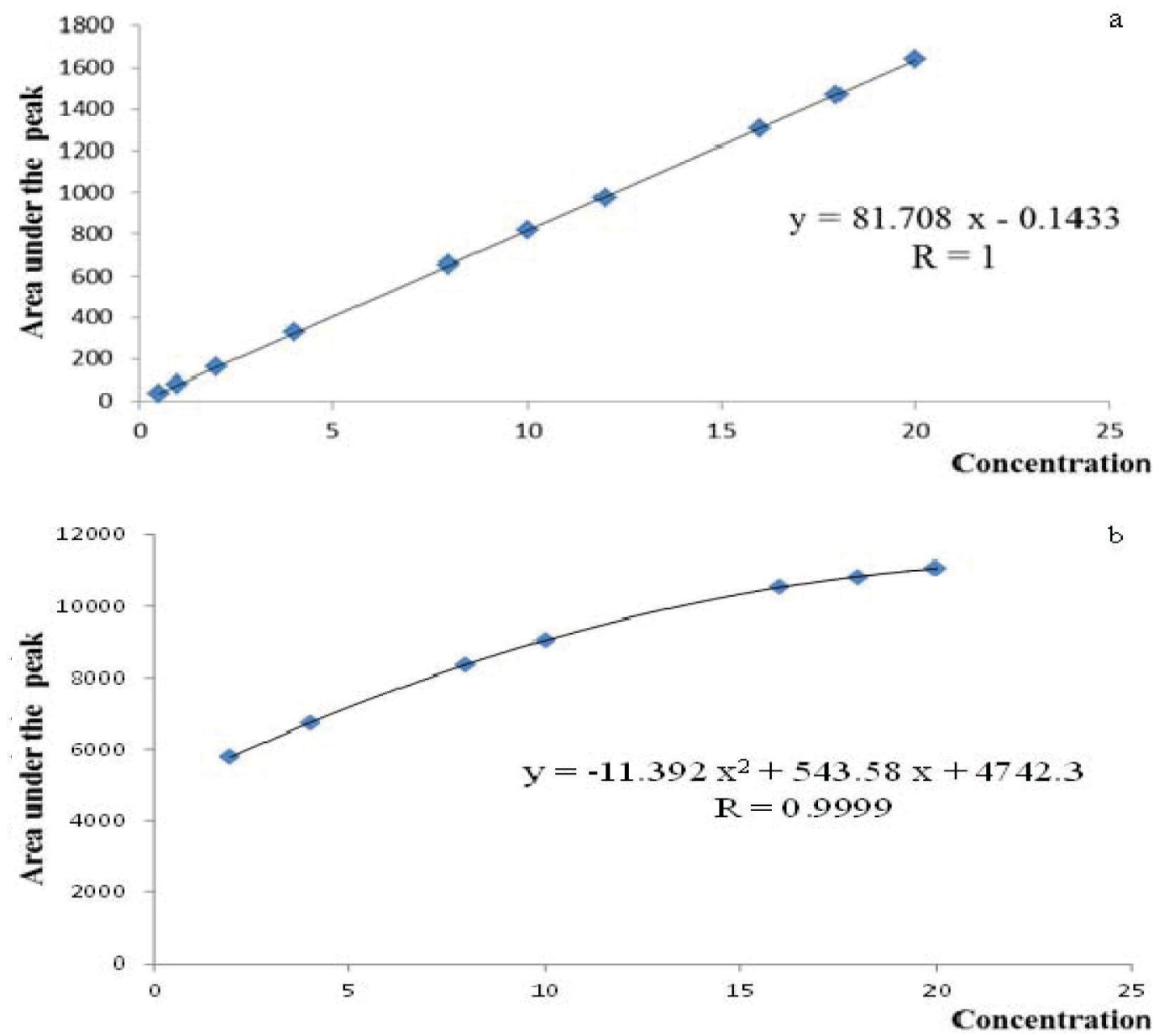

FIGURE 4 - a) HPLC linear relationship between peak areas and gliquidone (1-20 $\left.\mu \mathrm{g} \cdot \mathrm{mL}^{-1}\right)$ and b) binomial relationship between peak areas and gliquidone (2-20 $\mu \mathrm{g}$ /band). 
TABLE II - Performance data and validation parameters developed for HPLC and TLC methods

\begin{tabular}{ccc}
\hline Characteristic parameter & HPLC & TLC \\
\hline Range & $0.5-20 \mu \mathrm{g} \cdot \mathrm{mL}^{-1}$ & $2-20 \mu \mathrm{g} / \mathrm{band}$ \\
Slope & 81.708 & 543.58 for x \\
& & 11.392 for x$^{2}$ \\
SD of slope & 0.176 & ------ \\
Intercept & -0.143 & 4742.3 \\
SD of intercept & 2.018 & ------ \\
Correlation coefficient (r) & 1 & 0.9999 \\
LOD & $0.177 \mu \mathrm{g} \cdot \mathrm{mL}^{-1}$ & $0.261 \mu \mathrm{g} / \mathrm{band}$ \\
LOQ & $0.537 \mu \mathrm{g} \cdot \mathrm{mL}^{-1}$ & $0.791 \mu \mathrm{g} / \mathrm{band}$ \\
Residual sum of squares & 117.485 & ------ \\
Accuracy (\%recovery $\pm \% R S D)$ & & \\
Drug substance & $99.305 \pm 0.997$ & $99.991 \pm 1.055$ \\
Drug product & $103.304 \pm 0.514$ & $102.799 \pm 0.579$ \\
Precision (\%RSD) & & \\
Intra-day & 0.867 & 1.158 \\
Inter-day & 1.812 & 1.444 \\
Precision of instruments & 0.536 & 0.477 \\
\hline
\end{tabular}

\section{Accuracy}

Drug substance was analyzed using 3 concentrations of 9 determinations $\left(2,10,18 \mu \mathrm{g} \cdot \mathrm{mL}^{-1}\right)$ for HPLC and $(4,10,16 \mu \mathrm{g} / \mathrm{band})$ for TLC methods Table II. The drug product was assayed by HPLC and TLC methods and standard added technique was applied to demonstrate the accuracy of the methods. The results were expressed as percent recovery $\pm \% \mathrm{RSD}$. The calculated student's $\mathrm{t}$-test and the variance ratio $\mathrm{F}$ - test revealed no significant difference between the performance of both HPLC and TLC and the official method for tablets regarding accuracy and precision and the results were abridged in Table III (Agarwal, 2013).

\section{Precision}

The intra-day variability was assessed considering three concentration levels prepared in triplicate: 6,10 , and $14 \mu \mathrm{g} . \mathrm{mL}-1$ and 8,10 , and $12 \mu \mathrm{g} /$ band for the HPLC and TLC methods, respectively. Intermediate precision was determined by analyzing the same concentrations $n=9$ for HPLC and for TLC on three successive days to estimate inter-day variation. Precision results were expressed for each type as \%RSD as shown in Table II. The precision of instruments was checked by repeated measurement of the concentration $\left(10 \mu \mathrm{g} \cdot \mathrm{mL}^{-1}\right)$ for HPLC and $(10 \mu \mathrm{g} / \mathrm{band})$ for TLC for 6 times. \%RSD for measured peak areas by both HPLC and TLC procedures was found to be 0.536 and 0.477 , respectively. These values are bellow of that considered adequate $(1 \%)$ to ensure proper functioning of HPLC and TLC systems.

\section{$\angle O D$ and $L O Q$}

LOD and LOQ were calculated for both HPLC and TLC procedures by the method based on the standard deviation $\sigma$ of the response and the slope $S$ of the calibration curve using the following formula: $\operatorname{LOD}=3.3 \mathrm{\sigma} / \mathrm{S}$ and $\mathrm{LOQ}=10 \mathrm{\sigma} / \mathrm{S}$ and results are given in Table II.

\section{Robustness}

The robustness of analytical HPLC and TLC procedures is a measure of its capacity to remain unaffected by small but deliberate variation. For HPLC method the following parameters were tested: $\mathrm{pH}$ of mobile phase \pm 0.1 ; mobile phase composition $\pm 1 \%$, different $C_{18}$ columns (suppliers), column temperature $25 \pm 2{ }^{\circ} \mathrm{C}$, flow rate \pm 0.05 and wavelength \pm 1 . For TLC method: different plates (lots), developing system composition $\pm 1 \%$ and scanning wavelength \pm 2 . Negligible difference was found in \%RSD of response (0.56-1.65 for HPLC, 0.15-0.58 for TLC). Moreover, robustness of the proposed methods was concerned with the stability of solutions for 2 weeks and extraction time 10 - $30 \mathrm{~min}$.

\section{System suitability testing}

System suitability parameters were evaluated. ICH states that system suitability testing is an integral part 
TABLE III - Determination of gliquidone in pharmaceutical formulation by the proposed HPLC and TLC, application of the standard added technique and statistical comparison

\begin{tabular}{|c|c|c|c|c|}
\hline Item & Taken $\mu \mathrm{g} \cdot \mathrm{mL}^{-1}$ & Found $\mu \mathrm{g} . \mathrm{mL}^{-1}$ & \%Recovery & $\begin{array}{c}\text { \%Comparison method } \\
\text { (Brithish Pharmacopeia, 2016) }\end{array}$ \\
\hline HPLC method & $\begin{array}{c}1.8 \\
5.4 \\
10.8 \\
18\end{array}$ & $\begin{array}{c}1.869 \\
5.540 \\
11.147 \\
18.636\end{array}$ & $\begin{array}{l}103.85 \\
102.61 \\
103.21 \\
103.53\end{array}$ & $\begin{array}{l}103.20 \\
103.18 \\
102.85 \\
103.48\end{array}$ \\
\hline Mean $\bar{x} \pm$ SD & & & $103.30 \pm 0.530$ & $103.180 \pm 0.256$ \\
\hline SE & & & 0.265 & 0.128 \\
\hline t-test & & & $0.408(2.45)$ & \\
\hline F-test & & & $4.32(9.28)$ & \\
\hline Standard added to $5.4 \mu \mathrm{g} \cdot \mathrm{mL}^{-1}$ & $\begin{array}{c}2.7 \\
5.4 \\
10.8 \\
\end{array}$ & $\begin{array}{c}2.660 \\
5.319 \\
10.657 \\
\end{array}$ & $\begin{array}{l}98.54 \\
98.49 \\
98.68 \\
\end{array}$ & \\
\hline TLC method & $\begin{array}{c}3.6 \\
6 \\
8.4 \\
12 \\
18\end{array}$ & $\begin{array}{c}3.705 \\
6.114 \\
8.673 \\
12.404 \\
18.460\end{array}$ & $\begin{array}{l}102.92 \\
101.89 \\
103.25 \\
103.36 \\
102.56\end{array}$ & \\
\hline Mean $\bar{x} \pm$ SD & & & $102.80 \pm 0.595$ & \\
\hline SE & & & 0.266 & \\
\hline t-test & & & $1.287(2.36)$ & \\
\hline F-test & & & $5.446(9.12)$ & \\
\hline Standard added to $6 \mu \mathrm{g} / \mathrm{band}$ & $\begin{array}{c}3 \\
6 \\
12\end{array}$ & $\begin{array}{c}2.943 \\
5.945 \\
11.900\end{array}$ & $\begin{array}{l}98.131 \\
99.081 \\
99.172\end{array}$ & \\
\hline
\end{tabular}

Figures between parenthesis are the tabulated $\mathrm{t}$ and $\mathrm{F}$ - values (at degree of freedom $=4$ for comparison method, $=4$ for HPLC and $=5$ for TLC methods) at $\mathrm{p}=0.05$ (B.L.Agarwal, 2013).

of the chromatographic procedures.Capacity factor (k), asymmetry factor, resolution (Rs), selectivity $(\alpha)$ and number of theoretical plates $(\mathrm{N})$ were calculated for HPLC (United States Pharmacopeia, 2016) and TLC (Variyar, Chattyie, Sharma, 2011) methods and the results are given in Table IV.

\section{CONCLUSION}

Stability studies of gliquidone revealed its stability in thermal conditions and partially degraded under acid and base hydrolysis on cold, neutral hydrolysis and oxidation conditions. The drug was completely degraded

TABLE IV - System suitability parameters of HPLC and TLC methods developed for the determination of gliquidone

\begin{tabular}{lccc}
\hline Parameter & HPLC & TLC & Reference value \\
\hline Capacity factor $(\mathrm{K})$ & 1.8 & 0.613 & $1-10$ for HPLC \\
& & & $0-10$ for TLC \\
Resolution $(\mathrm{Rs})$ & 4.423 & 1.344 & Rs $>1$ \\
Selectivity $(\alpha)$ & 1.35 & 1.281 & $\sim 1$ \\
Symmetry factor & 0.99 & 1 & 1 \\
Height HETP(cm/plate ) & 0.007 & 0.004 & The smaller the value the higher the efficiency \\
Number of theoretical plates & 3445.7 & 1128.96 & Increase with efficiency of separation \\
Retardation factor \pm SD & $5.9 \pm 0.031$ & $0.60 \pm 0.01$ & \\
\hline
\end{tabular}


in acid and base hydrolytic conditions when refluxed for 9 hours. Results of HPLC and TLC showed the formation of mainly 3 detectable degradation products in acid and base media. The induced degradates were confirmed by LC - MS analysis and IR spectroscopy. Hence chromatographic techniques introduce a high separation power in pharmaceutical field so; HPLC and TLC have been developed for the separation of gliquidone and its degradation products. The cited methods were applicable for assay and purity testing of gliquidone in drug substance and drug product without interference of tablet excipients. The results obtained indicate that the introduced HPLC and TLC methods represent the sensitive, accurate, precise and rapid stability-indicating assays for gliquidone. Moreover, can be classified among the highly selective procedures and contribute to QC routine analysis.

\section{REFERENCES}

Agarwal BL. Basic statistics. 6th ed. New Delhi, India: New Age International; 2013.

Arayne MS, Sultana N, Mirza AZ, Shamshad H. Highperformance Liquid Chromatographic analysis of pioglitazone, gliquidone, rosuvastatin and simvastatin in formulations and human serum. Chin J Chem. 2010a;28(10):1998-2002.

Arayne MS, Sultana N, Mirza AZ. Spectrophotometric method for quantitative determination of gliquidone in bulk drug, pharmaceutical formulations and human serum. Pak J Pharm Sci. 2006;19(3):182-5

Arayne MS, Sultana N, Mirza AZ, Siddiqui FA. Validated RP-HPLC method for quantification of gliquidone in pharmaceutical formulation and human serum. J Chil Chem Soc. 2010b;55(2):156-8.

Brayfield A. Matindale The complete drug reference. 38th ed. London: Pharmaceutical Press; 2014.

Brithish Pharmacopeia. BP. London: TSO; 2016.

Cross AD. Introduction to practical Infra-Red spectroscopy. 2nd ed. London: Buttr WorthS; 1964.

El-Ghobashy MR, Yehia AM, Helmy AH, Youssef NF. Application of normal fluoresence and stability-indicating derivative synchronous fluoresence spectroscopy for the determination of gliquidone in presence of its fluorescent alkaline degradation product. Spectrochim Acta A Mol Biomol Spectrosc. 2018;188:619-25.
Food and Drug Administration. FDA. Guidance for industry: analytical procedures and methods validation: chemistry manufacturing, and controls documentation, draft guidance. Silver Spring, MD: Food and Drug Administration; 2000.

Görög S. Identification and determination of impurities in drugs. 2nd ed. Amsterdam: Elsevier Science Publishing; 2000.

Guo P, Li ZW, Chen CH, Deng SP, Tang SG.Direct injection of plasma to determine gliquidone in plasma using HPLC column switching technique. Yao Xue Xue Bao. 1992;27(6):452-5.

International Conference on Harmonization. ICH. Technical requirements for registration of pharmaceuticals for human use: stability testing of new drug substance and products Q1A (R2). Geneva; 2003a.

International Conference on HarmonizatioN. ICH. Technical requirments for registration of pharmaceuticals for human use: validation of analytical procedures-test and methodology Q2 (R1). Geneva; 2003b.

Maurer HH, Kratzsch C, Kraemer T, Peters FT, Weber AA. Screening, library-assisted identification and validated quantification of oral antidiabetics of the sulfonylurea-type in plasma by atmospheric pressure chemical ionization liquid chromatography-mass spectrometry. J Chromatogr B Analyt Technol Biomed Life Sci. 2002;773(1):63-73.

Sridevi S, Diwan PV.Validated HPLC method for the detrmination of gliquidone in rate plasma. Pharm Pharmacol Comm. 2000;6:303-7.

Torrinomedica. Glurenor. Available from: http://www. torrinomedica.it/farmaci/schedetecniche/Glurenor.asp\#SP13. 2015. [cited 2015 Dec 23].

United States Pharmacopeia. USP 1; 2016. p. 459.

Variyar PS, Chattyie S, Sharma A. Fundamentals and theory of HPTLC-based separation. In: Srivastava M, editor. High Performance Thin-Layer Chromatography (HPTLC). Berlin Heidelberd: Springer-Verlag; 2011. p. 27-40.

Received for publication on $01^{\text {st }}$ December 2016 Accepted for publication on $07^{\text {th }}$ November 2017 